\title{
High frequency of helicobacter negative gastritis in patients with Crohn's disease
}

\author{
L Halme, P Kärkkäinen, H Rautelin, T U Kosunen, P Sipponen
}

\begin{abstract}
The frequency of gastric Crohn's disease has been considered low. This study was undertaken to determine the prevalence of chronic gastritis and Helicobacter pylori infection in patients with Crohn's disease. Oesophagogastroduodenoscopy was performed on 62 consecutive patients suffering from ileocolonic Crohn's disease. Biopsy specimens from the antrum and corpus were processed for both histological and bacteriological examinations. $H$ pylori antibodies of IgG and IgA classes were measured in serum samples by enzyme immunoassay. Six patients $(9 \cdot 7 \%)$ were infected with $H$ pylori, as shown by histology, and in five of them the infection was also verified by serology. Twenty one patients $(32 \%)$ had chronic $H$ pylori negative gastritis (negative by both histology and serology) and one of them also had atrophy in the antrum and corpus. Granulomas were found in four patients. The characteristic appearance of $\boldsymbol{H}$ pylori negative gastritis was focal and mostly mild inflammation resembling the inflammatory changes seen in the gut in Crohn's disease. Patients with $H$ pylori negative chronic gastritis had a significantly more active disease in their gut than those with normal gastric mucosa $(p<0 \cdot 01)$. It is concluded that $H$ pylori positive gastritis is rare, while $H$ pylori negative gastritis is relatively common in patients with Crohn's disease. $H$ pylori negative 'Crohn's gastritis' seems to be associated with active Crohn's disease.

(Gut 1996; 38: 379-383)
\end{abstract}

Fourth Department of Surgery, Helsinki University Hospital, Finland

L Halme

Department of Pathology, University of Helsinki, Finland P Kärkkäinen

P Sipponen

Department of Bacteriology and Immunology,

University of Helsinki, Helsinki, Finland H Rautelin

T U Kosunen

Correspondence to: Dr L Halme, Fourth Department of Surgery, Helsinki University Hospital, Kasarmikatu $11-13$ FIN-00130 Helsinki, Finland.

Accepted for publication 7 September 1995
Keywords: Crohn's disease, gastritis, Helicobacter pylori.

The frequency of gastroduodenal Crohn's disease (CD) has been reported as $2-4 \%$ in patients with disease affecting the lower gastrointestinal tract. ${ }^{2}$ Recent reports indicate, however, that the frequency is higher, even more than $30 \%$, especially in children and adolescents. ${ }^{34}$ Sarcoid granulomas, diagnostic for $\mathrm{CD}$, are common in children and in patients with a short history of the disease. If granulomas are absent, gastroduodenal $C D$ is diagnosed by combining the clinical, radiological, endoscopic, and histological findings. ${ }^{35}$

More than $90 \%$ of patients with duodenal ulcers have gastritis associated with Helicobacter pylori infection. ${ }^{67}$ Recent reports have suggested that $C D$ can be one of the main causes of $H$ pylori negative duodenal ulcers. ${ }^{89}$
In a previous study we described upper gastrointestinal lesions characteristic of CD in $17 \%$ of patients with ileocolonic manifestations of the disease. ${ }^{10}$ Furthermore, $40 \%$ of these patients had chronic, non-specific gastritis. This study aimed to determine the prevalence of chronic gastritis and that of $H$ pylori infection in patients with $\mathrm{CD}$ who had undergone oesophagogastroduodenoscopy (OGDS) at the Fourth Department of Surgery, Helsinki University Hospital between 1989 and 1994.

\section{Patients and methods}

During a five year period from September 1989 to August 1994, OGDS was performed on 62 consecutive patients with $\mathrm{CD}$ to establish the distribution of their disease. During the study period, the OGDS was repeated (one to seven times) - on three patients because of anaemia and on five patients because of upper gastrointestinal complaints. Before OGDS, all patients were interviewed and their medical records were examined in order to register upper gastrointestinal symptoms or diseases or any other underlying diseases as well as possible antimicrobial and other medical treatments.

In all 62 patients (age: mean 41 years; range 23-76 years, gender: 35 males) the diagnosis of CD was based on the criteria described by Lennard-Jones. ${ }^{11}$ The mean (SD) duration of CD was 8.4 (5.4) years, range $0.5-23.4$ years. A small bowel disease pattern had been diagnosed in $33 \%$ of the patients, a large bowel one in $22 \%$, and a combined small and large bowel pattern in $45 \%$ of the patients. Before the primary OGDS, $76 \%$ of the patients had undergone at least one bowel resection. In two patients, duodenal involvement (based on radiological and endoscopical findings of duodenal strictures) had been previously diagnosed. One further patient had undergone gastric resection for stenosis of the pylorus, and granulomatous gastritis of an unknown origin had been verified three years before the diagnosis of $\mathrm{CD}$ in the ileum. In one patient, hypertrophic gastritis had been confirmed earlier on the basis of gastric specimens taken at laparotomy. In 14 of the 62 patients the primary OGDS was performed during an exacerbation of $\mathrm{CD}$ (duration of symptoms less than two weeks) in the gut, whereas 31 of the 62 patients had chronically active disease (duration of symptoms more than a month) in the gut and the disease of 17 patients was totally inactive when the OGDS was done. $\mathrm{CD}$ was classified as active if there was endoscopically and histologically or radiologically proved acute inflammation in the gut and the modified Harvey-Bradshaw index was $\geqslant 3.12$ 
TABLE I Prevalence of Helicobacter pylori infection as determined by histological findings of the gastric biopsy specimens $(n=62)$ and by detection of $\mathrm{H}$ pylori antibodies in serum samples $(n=61)$

\begin{tabular}{lcll}
\hline Type of gastritis & No (\%) & $\begin{array}{l}\text { Histology } \\
\text { H pylori }+v e\end{array}$ & $\begin{array}{l}\text { Antibodies } \\
\text { H pylori }+v e\end{array}$ \\
\hline Granulomatous gastritis & $1(2)$ & 1 & 1 \\
Hypertrophic gastritis & $1(2)$ & 0 & 0 \\
Chronic superficial gastritis & $22(35)$ & 2 & 2 \\
Atrophic gastritis & $3(5)$ & 2 & 2 \\
Acute erosions & $4(6)$ & 1 & 0 \\
Normal gastric mucosa & $31(50)$ & 0 & 0 \\
Total & 62 & 6 & 5
\end{tabular}

\section{ENDOSCOPY}

Multiple (three or more) biopsy samples from the antrum, corpus, and duodenum were systematically taken from macroscopically pathological and normal looking mucosal areas. Biopsy specimens from the oesophagus were taken only from macroscopically abnormal areas.

\section{HISTOLOGY}

The biopsy specimens were fixed in formalin and embedded in paraffin. The tissue sections were performed for morphological and bacteriological examination, using haematoxylin eosin (HE), Alcian blue ( $\mathrm{pH} 2 \cdot 5$ ) - periodic acid schiff, and modified Giemsa stains. All specimens were examined for typical features of Crohn's disease by two pathologists (PK and PS). The presence and type of chronic gastritis in the specimens taken from the antrum and corpus of the stomach were interpreted and scored according to the Sydney system. ${ }^{13}$ The presence of $H$ pylori infection in the specimens taken from the antrum and corpus was graded as 0 (no bacteria), 1 (minimal colonisation), 2 (moderate colonisation), and 3 (extensive colonisation).

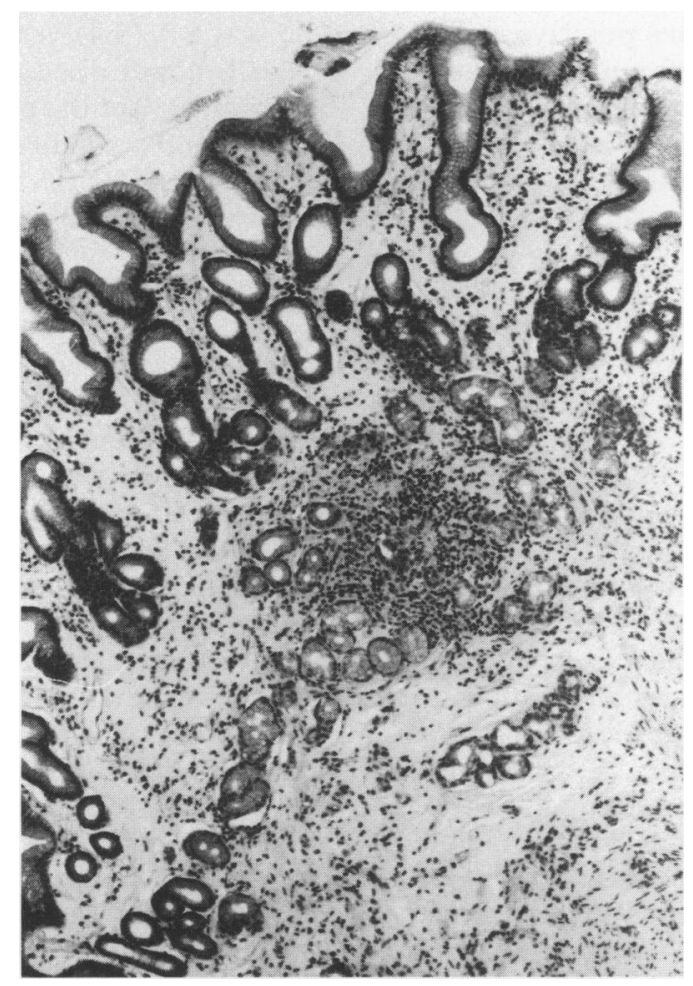

Figure 1: Focal inflammatory lesion in the antral mucosa resembling that seen in active Crohn's disease in the gut. (Haematoxylin and eosin stained: magnification $\times 100$.)

\section{ANTIBODY ASSAY}

Serum samples, taken at the time of OGDS, were available from 51 of 62 patients. In 10 further patients serum samples had been collected after the OGDS. One patient died during the study period, and no serum sample was available from him. Antibodies to $H$ pylor were measured separately for IgG, and IgA by enzyme immunoassay. ${ }^{14} 15$ The absorbance readings were converted to reciprocals of the end point titres. The end point titres were the dilutions of the serum at the cut off level defined by the optical densities of the positive reference serum pools at constant dilutions. The lower limits of raised titres (expressed as reciprocals) were 700 for IgG and 100 for IgA.

\section{STATISTICAL METHODS}

The Pearson's $\chi^{2}$ test and the Fisher's exact test were used.

\section{Results}

\section{ENDOSCOPICAL FINDINGS}

Twenty two patients had redness or oedema in the antrum or corpus mucosa. One patient had senosis of the pylorus, three further patients had stenosis of the duodenum, and one patient showed an incipient stenosis in the cardia. One patient had a deep ulceration in the cardia below the gastro-oesophageal junction, and five further patients had aphtous or deep longitudinal ulcerations in the duodenum.

\section{HISTOLOGICAL FINDINGS IN THE GASTRIC} MUCOSA

Six $(9 \cdot 7 \%)$ of the 62 patients studied showed $H$ pylori in their gastric biopsy specimens stained by modified Giemsa (Table I). The density of colonisation in the antral mucosa was moderate in two and extensive in four cases. $H$ pylori infection was graded as minimal in three patients, moderate in two, and extensive in one of the patients, when the mucosa of the body was considered. The histological findings of the biopsy specimens of the 62 patients are shown in Table I.

Twenty one patients (34\%) had $H$ pylori negative chronic gastritis. A characteristic appearance was a focal, patchy inflammation with polymorphonuclear, eosinophilic, and mononuclear cells destroying parts of the crypts (Fig 1). In a third of these patients the inflammation was graded as moderate or severe, and in these seven patients especially, the inflammatory changes in the gastric mucosa resembled those seen in the acute involvement of the gut in Crohn's disease. The patients with $H$ pylori negative gastritis had a significantly more active disease in the gut than those with normal gastric mucosa $(p<0.01$, Table II).

Four of the 62 patients showed microgranulomas in the gastric mucosa. One patient with $H$ pylori positive atrophic gastritis and a deep ulceration and an incipient stenosis in the upper cardia had a microgranuloma at the edge 
TABLE II Type of gastritis and activity and location of Crohn's disease (CD)

\begin{tabular}{|c|c|c|c|c|c|c|c|c|}
\hline \multirow[b]{2}{*}{$\begin{array}{l}\text { Type of gastritis } \\
(H P+v e / H P-v e)^{*}\end{array}$} & \multirow[b]{2}{*}{$\begin{array}{l}\text { No of } \\
\text { patients }\end{array}$} & \multicolumn{3}{|c|}{ Activity of $C D$} & \multicolumn{3}{|c|}{ Location of $C D$} & \multirow{2}{*}{$\begin{array}{l}\text { Involvement } \\
\text { of the } \\
\text { duodenum }\end{array}$} \\
\hline & & Acute & $\begin{array}{l}\text { Chronically } \\
\text { active }\end{array}$ & Inactive & $\begin{array}{l}\text { Small } \\
\text { bowel }\end{array}$ & $\begin{array}{l}\text { Large } \\
\text { bowel }\end{array}$ & Combined & \\
\hline Granulomatous gastritis $(\mathrm{HP}+\mathrm{ve})$ & 1 & 1 & - & - & 1 & - & - & - \\
\hline Hypertrophic gastritis (HP-ve) & 1 & - & 1 & - & 1 & - & - & - \\
\hline \multicolumn{9}{|l|}{ Chronic nonatrophic gastritis: } \\
\hline $\mathrm{HP}+\mathrm{ve}$ & 2 & 1 & 1 & - & 1 & 1 & - & - \\
\hline HP-ve & 20 & $8 \dagger$ & $11+$ & $1+$ & 6 & 3 & 11 & 4 \\
\hline \multicolumn{9}{|l|}{ Atrophic gastritis: } \\
\hline $\mathrm{HP}+\mathrm{ve}$ & 2 & - & 2 & - & 1 & - & 1 & - \\
\hline HP-ve & 1 & - & - & 1 & - & 1 & - & - \\
\hline \multicolumn{9}{|l|}{ Acute erosions: } \\
\hline $\mathrm{HP}+\mathrm{ve}$ & 1 & - & 1 & - & - & 1 & - & - \\
\hline $\mathrm{HP}$-ve & 3 & 2 & 1 & - & - & 2 & 1 & 2 \\
\hline Normal gastric mucosa $(\mathrm{HP}-\mathrm{ve})$ & 31 & $2 \dagger$ & $14 \dagger$ & $15 t$ & 12 & $\overline{6}$ & 13 & - \\
\hline
\end{tabular}

${ }^{\star} \mathrm{HP}+\mathrm{ve} / \mathrm{HP}-\mathrm{ve}=$ Helicobacter pylori negative and positive respectively. + Patients with non-atrophic $H$ pylori negative gastritis had significantly more active disease (acute or chronic) in the gut than patients with normal gastric mucosa $(\mathrm{p}<0 \cdot 01)$.

of the ulceration. On patient who had undergone gastric resection three years before CD was diagnosed showed granulomatous $H$ pylori positive gastritis verified in the resection specimen (Fig 2). Furthermore, two patients with $H$ pylori negative gastritis in the antrum showed microgranulomas.

\section{H PYLORI ANTIBODIES}

Five patients $(8 \cdot 1 \%)$ had high $H$ pylori antibody titres in the IgG class (Tables I and III) and three of these patients also had raised IgA antibody titres. One patient with acute erosions and extensive colonisation of $H$ pylori in the biopsy specimens did not show high antibody titres against $H$ pylori.

\section{PREVIOUS ANTIMICROBIAL TREATMENTS AND OTHER MEDICATIONS}

None of the patients studied had been treated for $H$ pylori infection. Two patients with $H$ pylori negative gastritis had been given ranitidine because of gastrointestinal symptoms, and one further patient with $H$ pylori positive gastritis had received omeprazole earlier. A total of 46 patients $(77 \%)$ had undergone gastrointestinal surgery and had been given antimicrobial prophylaxis or antimicrobial therapy lasting from one to 10 days and consisting of metronidazole

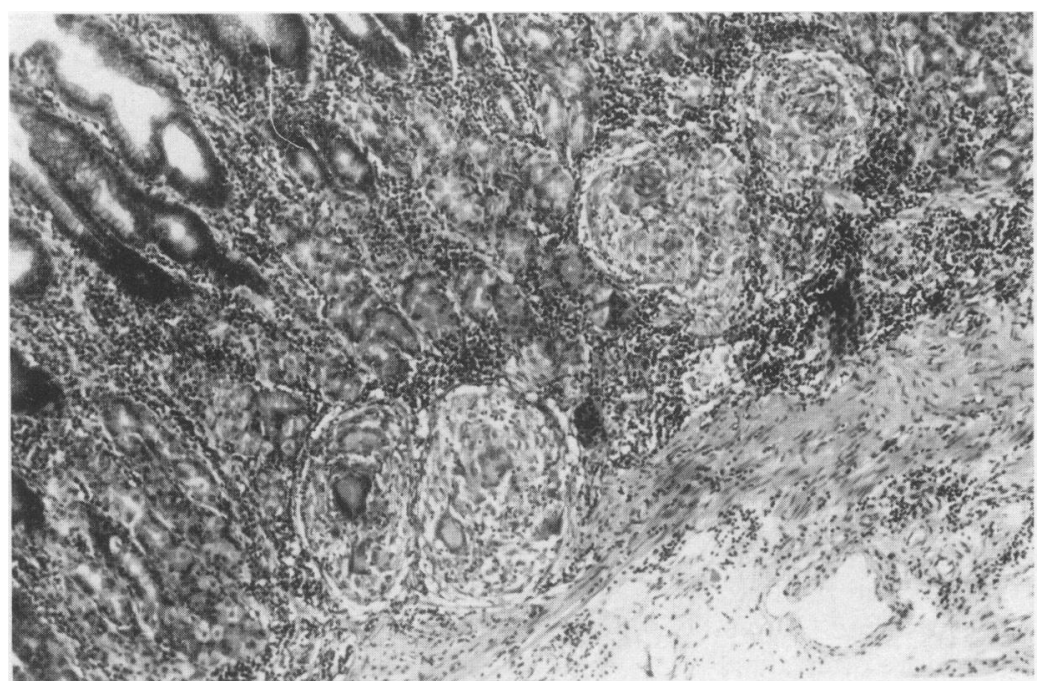

Figure 2: Granulomatous Helicobacter pylori positive gastritis in the resection specimen of the stomach. (Haematoxylin and eosin stained: magnification $\times 100$.) and cephalosporin or metronidazole and aminoglycoside. There was no association between gastrointestinal surgery and the presence or absence of $H$ pylori infection (Table III).

Medical treatments for Crohn's disease before the endoscopy are shown in Table III. Thirty eight patients had not received any medical treatment in the three months immediately before the endoscopy, but some had had antimicrobial prophylaxis or antimicrobial therapy of short duration earlier in connection with bowel surgery (Table III). There were no significant differences, however, in any medical treatment in the patients with gastritis or normal mucosa or in those with or without $H$ pylori infection (Table III).

No use of non-steroidal anti-inflammatory drugs or heavy alcohol consumption were reported. Fourteen of the patients were smokers but only three of these had $H$ pylori negative gastritis.

\section{Discussion}

The frequency of gastric $\mathrm{CD}$ has previously been considered to be low. ${ }^{25}$ This might have been due to difficulties in diagnosing typical radiological or endoscopic findings, such as strictures, aphtous or longitudinal ulcerations or cobble stone, as well as granulomas in histological specimens which are required for the diagnosis. Furthermore, it has been difficult to differentiate the inflammatory lesions seen in CD from other gastroduodenal diseases, particularly the peptic ulcer disease and ordinary $H$ pylori positive gastritis. In the present study, gastric microgranulomas were detected only in four $(6.5 \%)$ of the 62 patients. However, a third of the patients showed chronic $H$ pylori negative gastritis, the inflammatory changes of which resembled those seen in the active $C D$ in the gut. Thus, it seems that gastric involvement of $C D$ is not as rare as previously thought.

Most duodenal ulcer patients have antral gastritis, ${ }^{16}$ and in $90-100 \%$ of them $H$ pylori is found in the antral mucosa. ${ }^{67}$ According to a previous study of a Finnish population, the prevalence of $H$ pylori negative, non-atrophic gastritis was about $6 \%$ in 1977,1985 , and $1992 .{ }^{17}$ In the present study, only six patients with gastritis were shown to be infected by $H$ pylori, as determined by the histological 
TABLE III Helicobacter pylori antibody titres and medial treatment of patients with Crohn's disease (CD). There were no significant differences in medical therapy between patients with gastritis or with normal mucosa and between patients with or without $\mathrm{H}$ pylori infection

\begin{tabular}{|c|c|c|c|c|}
\hline & \multicolumn{3}{|c|}{ H pylori-ve patients } & \multirow{2}{*}{$\begin{array}{l}\text { H pylori +ve patients } \\
\begin{array}{l}\text { Chronic gastritis } \\
(n=6)\end{array}\end{array}$} \\
\hline & $\begin{array}{l}\text { Chronic gastritis } \\
(n=22)\end{array}$ & $\begin{array}{l}\text { Erosions } \\
(n=3)\end{array}$ & $\begin{array}{l}\text { Normal mucosa } \\
(n=31)\end{array}$ & \\
\hline \multicolumn{5}{|l|}{ Long term therapy for CD: } \\
\hline Sulphasalazine & 3 & - & 5 & 2 \\
\hline 5-aminosalicylic acid & 4 & - & 3 & 1 \\
\hline Metronidazole or ciprofloxacin & 4 & - & 2 & 1 \\
\hline Immunosuppressive drugs & - & - & 1 & - \\
\hline Corticosteroids (within 3 mths) & 3 & - & 2 & 1 \\
\hline \multicolumn{5}{|l|}{$\begin{array}{l}\text { History of antimicrobial prophylaxis or therapy } \\
\text { in connection with previous bowel surgery }\end{array}$} \\
\hline $1-3 \mathrm{~d}$ & 7 & 1 & 12 & - \\
\hline $4-10 d$ & 8 & 2 & 14 & 2 \\
\hline \multirow{3}{*}{$\begin{array}{l}\text { No antimicrobial therapy or previous surgery } \\
H \text { pylori antibody titres } t: \\
\text { Median (range) IgG titre } \\
\text { Median (range) IgA titre }\end{array}$} & 5 & - & 5 & $\overline{1}$ \\
\hline & $50(50-200)$ & $50(50)$ & $50(50-200)$ & $1500(200-3800) \ddagger$ \\
\hline & $5(5-20)$ & $10(5-20)$ & $5(5-90)$ & $110(20-160)$ \\
\hline
\end{tabular}

^In all patients bowel surgery was performed at least a year prior to endoscopy. Antimicrobial prophylaxis consisted of metronidazole and cephalosporin or metronidazole and aminoglycoside. †The lower limit of raised titres was 700 for IgG and 100 for IgA. $\neq$ One patient with $H$ pylori in the biopsy specimen did not show raised $H$ pylori antibody titres.

examination of Giemsa stained gastric biopsy specimens. The colonisation of $H$ pylori can be patchy on the gastric mucosa and therefore the prevalence of $H$ pylori in the present patients was confirmed by the determination of $H$ pylori antibodies in the serum samples. All except one of the patients with histologically proved $H$ pylori infection showed raised antibodies against $H$ pylori. No further $H$ pylori positive patients were found by serology. Thus, the prevalence of $H$ pylori infection in CD seems to be low.

In a recent report by El-Omar et al the prevalence of $H$ pylori infection was low in patients with an inflammatory bowel disease, including both the patients with ulcerative colitis and those with $\mathrm{CD} .{ }^{18}$ It was suggested that this might have been due to the eradication of $H$ pylori infection in patients with long term treatment with sulphasalazine. In the present study, 10 patients had been treated with long term sulphasalazine (Table III), and two of these patients were still $H$ pylori positive. In addition, as other antimicrobial treatments of long or short duration were considered, no significant differences were found between patients with gastritis or normal mucosa and between patients with or without $H$ pylori infection (Table III). Although the medical treatments given to these patients would, by some mechanism, have led to the eradication of $H$ pylori, the histological findings of focal inflammation can hardly be explained as sequelae of the eradication of $H$ pylori.

Our results support an earlier assumption that $\mathrm{CD}$ is a generalised inflammatory disease of the whole gastrointestinal tract. Before the era of $H$ pylori, focal gastric inflammatory changes similar to the present findings were described on the gastric mucosa of patients with CD by Korelitz et $a l^{19}$ and SchmitzMoormann et al. ${ }^{4}$ However, in those reports the diagnosis of gastric $\mathrm{CD}$ was confirmed by concomitant findings of granulomas and other findings characteristic of $\mathrm{CD}$. As the patients with $H$ pylori negative gastritis had active disease in the gut significantly more often than those with normal gastric mucosa, we suggest that gastric manifestations could be used as markers of an exacerbation of $\mathrm{CD}$ in the gut. A prospective study in which endoscopical biopsy specimens are taken during active and inactive periods of $\mathrm{CD}$ from $H$ pylori negative patients might give further information on the gastritis associated with this disease.

We conclude that the prevalence of the ordinary $H$ pylori positive gastritis is low in patients with $\mathrm{CD}$, but that $\mathrm{CD}$ associated $H$ pylori negative gastritis is relatively common. The diagnosis of this 'Crohn's gastritis' requires careful interpretation of endoscopic and histological findings and it has to be based on exclusion of other gastric diseases. In the present study gastric involvement of $\mathrm{CD}$ was shown to be more common than previously thought and associated with more severe diseases in the gut.

Some of these data were presented in an abstract entitled, "High frequency of helicobacter negative gastritis in patients with Crohn's disease" at the 4th United European Gastroenterology week, September 17-21, 1995.

1 Rutgeers P, Onette E, Vantrappen G, Geboes K, Broeckaert , Talloen L. Crohn's disease of the stomach and duodenum: A clinical study with emphasis on the value of endoscopy and endoscopic biopsies. Endoscopy 1980; 12: 288.

2 Fielding JF, Toye DKM, Beton DC, Cooke WT. Crohn's disease of the stomach and duodenum. Gut 1970; 11: 1001-6.

3 Mashako MNL, Cezard JP, Navarro J, Mougenot JF, Sonsino E, Gargouri A, et al. Crohn's disease lesions in the upper gastrointestinal tract: Correlation between clinical, radiological, endoscopic and histological features in adolescent and children. $\mathcal{F}$ Pediatr Gastroenterol Nutr 1989; 8: 442-6.

4 Schmitz-Moormann P, Malchow H, Pittner P. Endoscopic and bioptic study of the upper gastrointestinal tract in Crohn's disease patients. Pathol Res Pract 1985; 178 377-87.

5 Danzi JT, Farmer RG, Sullivan BH, Rankin GB Endoscopic features of gastroduodenal Crohn's disease. Gastroenterology 1976; 70: 9-13.

6 Marshall BJ, Warren JR. Unidentified curved bacilli on gastric epithelium in the stomach of patients with gastritis gastric epithelium in the stomach of patients with

7 Rauws EAJ, Langenberg W, Houthoff HJ, Zanen HC, Tytgat GNJ. Campylobacter pyloridis-associated chronic active antral gastritis. A prospective study of its prevalence and the effects of antibacterial and antiulcer treatment. Gastroenterology 1988; 94: 33-40.

8 Borody TJ, George LL, Brandl S, Andrews P, Ostapowicz $\mathrm{N}$, Hyland $\mathrm{L}$, et al. Helicobacter pylori-negative duodena ulcer. Am $\mathcal{F}$ Gastroenterol 1991; 86: 1154-7.

9 McColl KEL, El-Nujumi AM, Chittajallu RS, Dahill SW, Dorrian CA, El-Omar E, et al. A study of the pathogenesis of Helicobacter pylori negative chronic duodenal ulceration. Gut 1993; 34: 762-8.

10 Halme LEH, Sipponen PI, von Smitten KAJ. Involvement of gastroduodenal mucosa in Crohn's disease. Eur $\mathcal{F}$ of gastronterol Hepatol. 1992; 4: 23-8.

11 Lennard-Jones JE. Classification of inflammatory bowel disease. Scand f Gastroenterol 1989; 24: (suppl 170): 2-5. 
12 Myren J, Bouchier IAD, Watkinson G, Softley A, Clamp SE, de Dombal FT. The OMGE multinational inflammatory bowel disease survery 1976-1982. A further report on 2657 cases. Scand $\mathcal{F}$ Gastroenterol 1984; 23: (suppl 95): $1-27$

13 Price AB. The Sydney system: histological division. $\mathcal{f}$ Gastroenterol Hepatol 1991; 6: 209-22.

14 Kosunen TU, Höök J, Rautelin HI, Myllylä G. Age-dependent increase of Campylobacter pylori antibodies in blood dent increase of Campylobacter pylori antibodies

15 Kosunen TU, Seppälä K, Sarna S, Sipponen P. Diagnostic value of decreasing IgG, IgA and IgM antibody titres value of decreasing IgG, IgA and IgM antibody titres 339: 893-5.
16 Schrager J, Spink R, Mitra S. The antrum in patients with duodenal and gastric ulcers. Gut 1967; 8: 497-508

7 Sipponen P, Helske T, Järvinen P, Hyvärinen H, Seppälä K, Siurala $\mathbf{M}$. Fall in the prevalence of chronic gastritis over 15 years: analysis of outpatient series in Finland from 1977, 1985 and 1992. Gut 1994; 35: 1167-71.

18 El-Omar E, Penman I, Cruikshank G, Dover S, Banerjee S, Williams $C$, et al. Low prevalence of Helicobacter pylori in inflammatory bowel dis salazine. Gut 1994; 35: 1385-8.

19 Korelitz BI, Wayne JD, Kreuning J, Sommers SC, Fein $\mathrm{HD}$, Gelberg BJ, Crohn's disease in endoscopic biopsies of the gastric antrum and duodenum. Am $¥$ Gastroenterol 1981; 76: 103-9. 